\title{
Fen Bilgisi Eğitimi Anabilim Dalı'ndaki Öğretmen Adaylarının Kaynakların Tasarruflu Kullanımı Hakkındaki Görüşleri
}

\author{
DOI: 10.26466/opus.648555
}

\author{
İbrahim Yüksel * \\ * Dr., Gazi Üniversitesi, Gazi Eğitim Fakültesi, Ankara/Türkiye \\ E-Posta: ibrahimyuksel7@hotmail.com ORCID: 0000-0001-5686-9344
}

Öz

Bu araştırmada Fen Bilgisi Ĕ̆itimi Anabilim Dalı'ndaki öğretmen adaylarının kaynakların tasarruflu kullanımı konusundaki görüşlerinin belirlenmesi amaçlanmıştır. Araştırma 2018-2019 eğitim öğretim yilının bahar döneminde bir devlet üniversitesinin eğitim fakültesinde Fen Bilgisi Ĕ̆itimi Anabilim Dalı'nda öğrenim gören 127 gönüllü öğretmen adayı ile gerçekleştirilmiştir. Araştırma nitel boyutta olup, durum çalışması yöntemine başvurulmuştur. Veri toplama aracı olarak, Türkiye'de konu ile ilgili kapsaml alanyazın taraması sonrası alanında uzman 4 kişinin görüşü alınarak araştırmacı tarafından geliştirilen 6 açık uçlu soru içeren görüşme formu kullanılmış ve toplanan veriler içerik analizi ile değerlendirilmiştir. Araştırma sonucunda, Fen Bilgisi öğretmen adaylarının sürdürülebilir kalkınma denince aklınıza ne geliyor konusunda "kaynakların tasarruflu kullanımı"; kaynakların tasarruflu kullanımı üzerine eğitim alıp almadıkları konusunda "almadıkları"; basit önlemler alarak su tasarrufu yapıp yapmadıkları konusunda "musluklardaki teknik problemlerin giderilmesi"; ülkemizdeki üniversitelerde kaynakların tasarruflu kullanımı ile ilgili yeterli eğitimin verilip verilmediğ i konusunda "yeterli eğitimin verilmediği"; ortaokullarda okutulan 2018 Fen Bilimleri müfredatında kaynakların tasarruflu kullanım ile ilgili yeterli düzeyde bilgi yer alıp almadığı konusunda "yeterli düzeyde bilgi verilmediği" ve ülkemizde 1 Ocak 2019 tarihinden itibaren marketlerde verilen taşıma poşetleri için talep edilen 25 kuruşluk ücretin kaynakların tasarruflu kullanımı için yeterli olup olmadığı konusunda "olmadı̆̆ğ" en çok frekansa sahip olan yanıtlardır.

Anahtar Kelimeler: Fen bilgisi eğitimi, öğretmen adayları, kaynakların tasarruflu kullanımı

9-12 Ekim 2019 tarihlerinde VII. Uluslararası Eğitim Programları ve Öğretim Kongresi (ICCIEPOK 2019)'nde bildiri olarak sunulmuştur. 


\title{
Opinions of Teacher Candidates in Science Education on the Efficient Use of Resources
}

$*$

\author{
İbrahim Yüksel
}

\begin{abstract}
In this study, it was aimed to determine the opinions of science teacher candidates about the efficient use of resources. The study was carried out with 127 volunteer teacher candidates studying in the Department of Science Education in the faculty of education of a state university in the spring semester of 2018-2019 academic year. The research was qualitative and case study method was used. As the data collection tool, the opinion form, including six open-ended questions, developed by the researcher by asking the opinions of 4 experts after an extensive literature analysis about the topic in Turkey was used and collected data were analyzed using content analysis. The most frequent frequencies of the questions are as follows. About what comes to your mind about sustainable development "saving use of resources", about whether they had education in saving use of resources "they didn't have", about whether they are saving water by taking simple measures "eliminating technical problems in taps", about whether adequate education is provided on the efficient use of resources in the universities in our country "not adequate education", about whether the 2018 science curriculum in secondary schools includes sufficient information on the efficient use of resources "not sufficient information", about whether in our country, since January 1, 2019, the demand of 25 cents for the transport bags given in the markets is sufficient for the efficient use of resources "not sufficient" have the highest frequency.
\end{abstract}

Keywords: Science education, teacher candidates, efficient use of resources

9-12 Ekim 2019 tarihlerinde VII. Uluslararası Eğitim Programları ve Öğretim Kongresi (ICCIEPOK 2019)'nde bildiri olarak sunulmuştur. 


\section{Giriş}

Günümüzde dünya nüfusunun artmasiyla enerjiye olan ihtiyaç artmakta fakat enerji kaynakları giderek azalmaktadır. Bu nedenle enerji kaynaklarının verimli bir şekilde kullanılması gerekmektedir. Yaşamı kolaylaştıran teknolojik araçların kullanımının artması ve bu araçların enerji ile çalışması enerji sorununu küresel bir problem haline getirmektedir. 2019 yılında yayımlanan Birleşmiş Milletler "Dünya Nüfus Beklentisi" raporuna göre ortalama 7,7 milyar olan dünya nüfusunun, 2050 yılında 9,7 milyara, 2100 yılında ise 10,9 milyara ulaşması beklenmektedir (URL 1). Bu durumun olumsuz etkilerini azaltmak için enerji kaynaklarının doğru ve etkili şekilde kullanılması adına yapılacak olan eğitimin niteliği büyük önem taşımaktadır (Güneş, Alat ve Gözüm, 2013).

İş hayatından ev hayatına, aydınlatmadan ısınmaya kadar günlük faaliyetlerin birçoğunda enerjiye ihtiyaç duyulmaktadır. Gerekli enerjinin üretilmesini sağlayan kaynaklar yenilenebilir ve yenilenemez olarak sinffland1rılmaktadır. Bu açıdan bakıldığında, bazı enerji kaynaklarının oluşumlarının, dolayısıyla yenilenmelerinin çok uzun zaman aldığı için yenilenemez olarak nitelendirildiği ifade edilmektedir (Şarlak, 2012). Enerji türlerine ait avantaj ve dezavantajlar Tablo 1'de (Şarlak, 2012) verilmiştir.

Tablo 1. Enerji türlerinin avantajları ve dezavantajlar

\begin{tabular}{|c|c|c|}
\hline Enerji Türü & Avantajları & Dezavantajları \\
\hline $\begin{array}{l}\text { Yenilenemeyen } \\
\text { Enerji Kaynakları }\end{array}$ & $\begin{array}{l}\text { - Kisa sürede fazla enerji sağlar. } \\
\text { - Ucuzdur. } \\
\text { - Verimi yüksektir. }\end{array}$ & $\begin{array}{ll}\text { - } & \text { Rezervleri sınırlıdır. } \\
\text { - } & \text { Ithalat bağımlılı̆ına neden } \\
\text { olur. } \\
\text { - } \quad \begin{array}{l}\text { Fiyat değişkenliği ve fiyat } \\
\text { riskleri vardır. } \\
\text { - Insan sağlığına ve çevreye } \\
\text { zararlıdır. }\end{array} \\
\end{array}$ \\
\hline $\begin{array}{l}\text { Yenilenebilir } \\
\text { Enerji Kaynakları }\end{array}$ & $\begin{array}{l}\text { - Tükenmez. } \\
\text { - Temizdir. } \\
\text { • Hava kirliliği sorunu oluşturmaz. } \\
\text { - İthalat bağımlılığını önler. } \\
\text { - Ülke için enerji güvenliği sağlar. } \\
\text { - Enerji üzerinden oluşan devletlera- } \\
\text { rası anlaşmazlıkları önler. }\end{array}$ & $\begin{array}{ll}\text { - } & \text { Alt yapı gerektirir. } \\
\text { - } & \text { Verimi düşüktür. } \\
\text { Mevsime ya da hava } \\
\text { durumuna bağlıdır. }\end{array}$ \\
\hline
\end{tabular}

Tablo 1 incelendiğinde enerji türlerinin dezavantajlarının rezervlerin s1nırlı olması, ithalat bağımlılığına neden olması, fiyat değişkenliği ve fiyat 
risklerinin olması, insan sağlığına ve çevreye zararlı olması, alt yapı gerektirmesi, veriminin düşük olması, mevsime ya da hava durumuna bağlı olması olarak sıralandığı görülmektedir (Şarlak, 2012). Nitekim bizler, kaynakları tasarruflu kullanarak gelecek nesillere birakırız ve bu sayede tasarruf edebileceğimiz her birim enerji ile de hem ülkemize hem de ekonomimize katkı sağlamış oluruz.

Kaynakların bilinçli kullanılmasına dikkat etme ve proje tasarımı ile katı atıkların geri dönüşümünün ülke ekonomisine katkısı ve bu konuya dair çözüm önerileri sunma kazanımları, 2013 yılındaki Fen Bilimleri öğretim programında "Canlılar ve Enerji İlişkileri" ünitesinde yer alırken, 2018 yılındaki Fen Bilimleri öğretim programında "Enerji Dönüşümleri ve Çevre Bilimi" ünitesinde ortak kazanımlar olarak yer almıştır. Buna ilaveten, 2013 yılındaki Fen Bilimleri öğretim programında elektrik ve su kaynaklarının bilinçli kullanılmasına yönelik özel kazanımlar yer alırken, 2018 yılındaki Fen Bilimleri öğretim programında "İnsan ve Çevre" ünitesinde kaynakları bilinçli kullanma ve geri dönüşümün önemi hakkında daha genel kazanımlar yer almıştır. Ayrıca, 2018 yılındaki Fen Bilimleri öğretim programında "Enerji Dönüşümleri ve Çevre Bilimi" ünitesinde; küresel iklim değişikliğinin nedenleri ve olası sonuçlarını tartışma, kaynakların tasarruflu kullanılmamasının olumsuz sonuçları ve gelecekte karşılaşılması muhtemel problemlere karşın çözüm önerilerinde bulunmaya yönelik kazanımlara yer verilmiştir. Bu doğrultuda, elektrik enerjisinin bilinçli ve tasarruflu kullanılması için evlerde elektriği tasarruflu kullanma ile ilgili kazanımlar vurgulanmıştır (Deveci, 2018).

2018 yılındaki Fen Bilimleri öğretim programı kapsamında öğrencilerin dönem sonunda Fen, Mühendislik ve Girişimcilik Uygulamaları kapsamında eğitim-öğretim yılı içerisinde ortaya çıkardıkları ürünü bilim şenliğinde sunmaları hedeflenmektedir. Bu kapsamda sıfır atık, yenilenebilir enerji, küresel iklim değişimi, sürdürülebilir kalkınma vb. problem alanları projelendirilerek öğretim programının doğrudan yaşam becerilerine yansıması etkili hale getirilebilir. Literatürde bu konuların öğretmen eğitimi ve öğrenci uygulamaları açısından toplumların yaşanabilir bir dünya ve gelecek tasarımını inşa edebilmesi odağında eğitimin rolü, katma değeri, yaygın etkisi, sürdürülebilirliği vb. açlardan çalışmanın özgün değerine ve önemine katkıda bulunabilir. 
Doğal kaynakların oluşumu için çok uzun zaman geçmesi gerekir. Dünya nüfusunun artışı göz önünde bulundurulduğunda doğal kaynakların yeterliliği sınırlı kalmaktadır. Bundan dolayı kaynakların tasarruflu kullanılması ve bilinçsiz bir şekilde tüketilmemesi gerekir. Bilinçsiz yere harcanan kaynaklarımız doğal dengenin bozulmasına neden olur. Nitekim Newborough ve Probert (1994)'a göre enerji ile ilgili yeterli düzeyde bilinç sahibi olunmaması, bu konu ile ilgili eğitim almamaktan ve ilgisizlikten kaynaklanmaktadır. Bu açıdan okullarımız, çocukluk çağından itibaren enerji bilincinin gelişmesinde temel oluşturmaktadır. Çocuklar okuldan aldıkları eğitim sayesinde çevreye duyarlı ve bilinçli vatandaşlar olarak yetişirler (Dias, Mattos \& Balestieri, 2004). Bu açıdan en önemli görev, kaynakların tasarruflu kullanılması konusunda öğrencilere küçük yaşlardan itibaren farkındalık oluşturmaktan sorumlu olan öğretmenlere, öğretmen adaylarına ve ailelere düşmektedir.

Araştırmanın problem cümlesi, “Fen Bilgisi Eğitimi Anabilim Dalı'ndaki öğretmen adaylarının kaynakların tasarruflu kullanımı konusu ile ilgili görüşleri nasıldır?" şeklinde ifade edilebilir. Araştırmanın amacı ise, Fen Bilgisi Eğitimi Anabilim Dalı'ndaki öğretmen adaylarında kaynakların tasarruflu kullanımı konusunda görüşlerini belirlemektir.

\section{Yöntem}

$\mathrm{Bu}$ araştırma nitel boyutta olup durum çalışması yöntemine başvurulmuştur. Durum çalışması, bir olayın derinlemesine incelenmesinin yanısıra bir olayı çeşitli olgularla ilişkilendirip, araştırılan bulgulara bütüncül bir nitelik de kazandırabilmektedir. Bunun yanında diğer yöntemlerle gözden kaçırılabilecek bilgilerin derinlemesine analizine de imkân sağlar (Punch, 2014). Araştırma 2018-2019 eğitim öğretim yılının bahar döneminde bir devlet üniversitesinin eğitim fakültesinde Fen Bilgisi Eğitimi Anabilim Dalı'nda öğrenim gören 127 gönüllü öğretmen adayı ile gerçekleştirilmiştir. Veri toplama aracı olarak, Türkiye'de konu ile ilgili yapılan çalışmalar incelenmiş ve kapsamlı alanyazın taraması sonrası 9 açı uçlu soru hazırlanmıştır. Uzman görüşleri doğrultusunda benzer sorular çıkartılmıştır. Çevre eğitimi alanında 4 uzmanın görüşü alınarak araştırmacı tarafından geliştirilen ve kaynakların tasarruflu kullanımı konusunda 6 açık uçlu soru içeren görüş formu kullanılmıştır. Fen Bilgisi Eğitimi Anabilim Dalı'ndaki öğretmen adaylarının 
kaynakların tasarruflu kullanımı konusu ile ilgili görüşleri içerik analizi ile değerlendirilmiştir. Araştırmada görüşme formundan elde edilen cevaplar kodlanmıştır. Kodlardan yola çıkılarak yorumlamalar yapılmıştır. Öğretmen adayları AÖ1... AÖ127 arasında numaralandırılmıştır.

Miles ve Huberman (1994)'a göre araştırmacılar aynı verileri kullanarak kodlama yaptı̆̆ takdirde ifadeler daha net hale gelmektedir. Bu şekilde kodlamaların ne ifade ettiği ve hangisinin hangi koda ait olduğu hakkında ortak kanıya ulaşmak kolaylaşır. Üzerinde uzlaşılan kod sayısının toplam kod sayısına (toplam kod sayısı = uzlaşılan kod sayısı + uzlaşılamayan kod sayısı) bölünmesiyle kodlayıcılar arası güvenilirlik oranı hesaplanabilir (Miles ve Huberman, 1994). Araştırmada kod sayısı iki uzman tarafından belirlenerek kodlayıcılar arası güvenirlik değeri \% 95 çıkmıştır.

\section{Bulgular}

Öğretmen adaylarının "Sürdürülebilir kalkınma deyince aklınıza ne/neler geliyor?" sorusuna ait görüşlerinden elde edilen kodlar Tablo 2'de verilmiştir.

Tablo 2. Sürdürebilir kalkınmanın tanımına ilişkin görüşler

\begin{tabular}{ll}
\hline Kod & Frekans \\
\hline Kaynakların tasarruflu kullanımı & 44 \\
Geri dönüşüm & 35 \\
Gelecek nesillerin ihtiyaçlarının karşılanması & 27 \\
Ekonomiye katkı sağlama & 22 \\
Çevreyi koruma & 21 \\
\hline Toplam & 149 \\
\hline
\end{tabular}

Tablo 2 incelendiğinde öğretmen adaylarının sürdürülebilir kalkınmanın tanımına ilişkin görüşlerini kaynakların tasarruflu kullanımı (f:44), geri dönüşüm (f:35), gelecek nesillerin ihtiyaçlarının karşılanması (f:27), ekonomiye katkı sağlama (f:22), çevreyi koruma (f:21) olarak ifade ettikleri belirlenmiştir. Öğretmen adaylarının görüşlerinden yapılan bazı doğrudan alıntılar aşağıda verilmiştir.

- ÖA51: "Ekonomiyi, çevreyi koruyarak yapılan kalkınmadır. Geri dönüşüm yapılacak kaynakları tasarruflu kullanarak destek oluruz." 
- ÖAs7: "Sürdürebilir kalkmma; planl, programl kaynaklarm tasarruflu kullanıldığı, sürekli olan kalkınma programıdır."

- ÖA117: "Kaynaklarnn tasarruflu kullamlip doğaya zarar vermeden geri dönüşı̈̈rülmesidir."

Katılımcılara kaynakların tasarruflu kullanımı konusunda eğitim alıp almadıkları sorulmuş ve görüşlerinden elde edilen kodlar Tablo 3'te verilmiştir.

Tablo 3. Kaynakların tasarruflu kullanımı ile ilgili eğitim alınma durumu

\begin{tabular}{ll}
\hline Kod & Frekans \\
\hline Ĕ̈itim almadı & 105 \\
Eğitim aldı & 13 \\
\hline Toplam & 118 \\
\hline
\end{tabular}

Tablo 3'e göre öğretmen adaylarının kaynakların tasarruflu kullanımı ile ilgili eğitim almadıkları (f:105) belirlenmiştir. Ayrıca, kaynakların tasarruflu kullanımı üzerine eğitim alan 13 öğretmen adayının kaynakların tasarruflu kullanımı hakkında eğitim aldıklarını ve bilinçli olduklarını vurguladıkları tespit edilmiştir. 105 öğretmen adayı bu konuda eğitim almadığını söylemiştir. Eğitim aldığını söyleyen öğretmen adaylarına ise ne tür eğitim aldıkları sorulmuştur. Bazı öğretmen adaylarının görüşlerinden yapılan doğrudan alıntılar aşağıda verilmiştir:

- ÖA7: "Sıfir atık projesi hakkında eğitim aldım ve videolarım izledim. Beni olumlu yönde çok etkiledi videolar. Konu hakkında bilinçlenmemi sağladı."

- ÖA12: "Aldığım eğitimle tasarruflu olmayı ve kaynakları idareli kullanmayı öğrendim."

- ÖA21: "Üniversitede çevre dersinde eğitim aldım. Bu eğitim sonucunda atık maddelerin ayrışttrıldığı geri dönüşüm kutuları bulundurmaya özen gösterdim."

Öğretmen adaylarının "Su yaşamımız için vazgeçilmez bir kaynaktır. Temizlik ve içme suyu ihtiyacının giderilmesinde kullanılır. Ayrıca birçok canlının yaşam alanıdır. Basit önlemler alarak su tasarrufu yapabilir misiniz? Açıklayınız." sorusuna ait görüşlerinden elde edilen kodlar Tablo 4'te verilmiştir. 
Tablo 4. Su tasarrufuna ilişkin görüşler

\begin{tabular}{ll}
\hline Kod & Frekans \\
\hline Musluklardaki teknik problemlerin giderilmesi & 37 \\
Diş fırçalarken suyu az kullanma & 29 \\
Bulaşıların el yerine makinede yıkanması & 19 \\
Duş alma süresinin azaltılması & 16 \\
Ev temizliği & 6 \\
\hline Toplam & 107 \\
\hline
\end{tabular}

Tablo 4'e göre öğretmen adaylarının su tasarrufuna ilişkin görüşlerini "musluklardaki teknik problemlerin giderilmesi (f:37), diş fırçalarken suyu az kullanma (f:29), bulaşıkların el yerine makinede yıkanması (f:19), duş alma süresinin azaltılması (f:16), ev temizliği (f:6)" olarak ifade ettikleri belirlenmiştir. Öğretmen adaylarının görüşlerinden doğrudan alınan bazı ifadeler aşağıda verilmiştir.

- ÖA13:"Duş sürelerini kısaltabiliriz. Bulaşıklar el yerine makinede yıkanmalıdir."

- ÖA38: "Musluklar tamir ettirilip damlayan sudan tasarruf yapılmalıdir. Ellerimizi yıkarken, banyo yaparken ihtiyacimiz kadar su kullanmalıyı."

- ÖA124: "Bulaşıkları elde yıkamamak, dişlerimizi firçalarken suyu kapatmak gibi basit önlemler alnabilir."

Öğretmen adaylarına ülkemizdeki üniversitelerde kaynakların tasarruflu kullanımı ile ilgili yeterli eğitim verilip verilmediği sorulmuş ve görüşlerinden elde edilen kodlar Tablo 5'te verilmiştir.

Tablo 5. Verilen eğitimin yeterliliğine ilişkin görüşler

\begin{tabular}{ll}
\hline Kod & Frekans \\
\hline Eğitim yeterli değil & 118 \\
Eğitim yeterli & 9 \\
\hline Toplam & 127 \\
\hline
\end{tabular}

Tablo 5'e göre öğretmen adayları ülkemizdeki üniversitelerde kaynakların tasarruflu kullanımı ile ilgili yeterli eğitim verilmediğini (f:118) ifade etmişlerdir. Bu konuda eğitim alan 9 öğretmen adayı ise ülkemizdeki üniversitelerde kaynakların tasarruflu kullanımı ile ilgili derslerde eğitim aldıklarını vurgulamışlardır. Bazı öğretmen adaylarının görüşlerinden yapılan doğrudan alıntılar aşağıda verilmiştir: 
- $\quad O ̈ A_{21}:$ "Eğitim veriliyor ancak eğitimin yeterli düzeyde olmadığını düşünüyorum. Sözel olarak kahyor. Uygulamaya geçirilme konusunda bir yöntem olmayinca yeterli olmuyor."

- ÖA47: "Yeterli eğitim verilmiyor. Sular, ışıklar açık kalıyor ve önemsenmiyor."

- ÖA56: "Fen bilgisi derslerinde kaynakların tasarruflu kullanımı üzerinde duruluyor. Yani gerekli önem veriliyor."

Öğretmen adaylarının “Ortaokullarda öğrenimi gerçekleştirilen 2018 Fen Bilimleri dersi müfredatında kaynakların tasarruflu kullanımı ile ilgili yeterli düzeyde bilgi yer aldığın düşünüyor musunuz?" sorusuna ait görüşlerinden elde edilen kodlar Tablo 6'da verilmiştir.

Tablo 6. 2018 Fen Bilimleri dersi müfredatında kaynakların tasarruflu kullanımının yeterliliğine ilişkin görüşler

\begin{tabular}{ll}
\hline \multicolumn{1}{c}{ Kod } & Frekans \\
\hline Müfredat yeterli değil & 68 \\
Müfredat yeterli & 54 \\
\hline Toplam & 122 \\
\hline
\end{tabular}

Tablo 6'ya göre öğretmen adayları 2018 Fen Bilimleri dersi müfredatında kaynakların tasarruflu kullanımı ile ilgili yeterli düzeyde bilgi yer almadı̆̆gnı (f:68) belirttiği tespit edilmiştir. 54 Öğretmen adayı ise yeterli düzeyde olduğunu ifade etmişlerdir. Bazı öğretmen adaylarının görüşlerinden yapılan doğrudan alıntılar aşağıda verilmiştir:

- ÖA56: "Yeterli düzeyde bilginin olduğu ancak aktarılmadığını düşünüyorum. Sadece kitaba bağh kalmayıp uygulamalı eğitimler yapılabilir."

- ÖA57: "Ĕ̆itimler verilmeli ancak yeterli olabilmesi için uygulama ile birlikte olmalıdır. Uygulama konusunda başarılı değiliz."

- ÖA127: "Yeterli değil. Etkinliklerle, gezilerle vb. uygulamalarla kaynakların tasarruflu kullanımı aktarılmalıdır."

Öğretmen adaylarına yöneltilen “Ülkemizde 1 Ocak 2019 tarihinden itibaren marketlerde verilen taşıma poşetleri için 25 kuruşluk bir ücret talep edilmektedir. Sizce bu uygulama sürdürülebilir kalkınma için yeterli midir? Açılayınız." sorusuna ait öğretmen adaylarının görüşlerinden elde edilen kodlar Tablo 7'de verilmiştir. 
Tablo 7. Poşet için ücret talebi sürdürülebilir kalkınma hakkındaki görüşler

\begin{tabular}{ll}
\hline Kod & Frekans \\
\hline Yeterli değil & 104 \\
Yeterli & 20 \\
\hline Toplam & 124 \\
\hline
\end{tabular}

Tablo 7'ye göre öğretmen adayları poşet için ücret talebinin sürdürülebilir kalkınma için yeterli olmadığını (f:104) belirtmişlerdir. Bazı öğretmen adaylarının görüşlerinden yapılan doğrudan alıntılar aşağıda verilmiştir:

ÖAss: "Yeterli değildir. Poşet kullanımı azalmış ancak diğer alanlarda yapılan çalışmalar yeterli değil."

- ÖA117: "Yeterlidir. Plastiklerin çevredeki kirlilik oluşturmaları azalmıştır."

- ÖA119: "Yeterli değildir. İnsanlar için başlangıç ve bilinçlendirme olmuştur. Bu gerekli alanlara başka yöntemlerle uygulanabilir, güzel örnek teşkil eder."

\section{Tartışma, Sonuç ve Öneriler}

Fen Bilgisi Eğitimi Anabilim Dalı'ndaki öğretmen adaylarının kaynakların tasarruflu kullanımı hakkındaki görüşlerinin belirlenmesi amacıyla yapılan araştırma sonucunda öğretmen adaylarının,

- Sürdürülebilir kaynakların tasarruflu kullanımı, geri dönüşüm, gelecek nesillerin ihtiyaçlarının karşılanması, ekonomiye katkı sağlama, çevreyi koruma kavramları ile bağdaştırdıkları,

- Kaynakların tasarruflu kullanımı ile ilgili eğitim almadıkları,

- Su tasarrufu yapmayı "musluklardaki teknik problemlerin giderilmesi, diş firçalarken suyu az kullanma, bulaşıkların el yerine makinede yıkanması, duş alma süresinin azaltılması, ev temizliği" ile ilişkilendirdikleri,

- Ülkemizdeki üniversitelerde kaynakların tasarruflu kullanımı ile ilgili yeterli eğitim verilmediğini ifade ettikleri,

- 2018 Fen Bilimleri dersi müfredatında kaynakların tasarruflu kullanımı ile ilgili yeterli düzeyde bilgi yer almadığını düşündükleri ve

- Poşet için ücret talebinin sürdürülebilir kalkınma için yeterli olmadığını belirttikleri sonucuna ulaşılmıştır. 
Ayrıca, öğretmen adaylarının sürdürülebilir kalkınmayı kaynakların tasarruflu kullanımı, geri dönüşüm vb. kavramlar ile ilişkilendirdikleri görülmüştür. Benzer şekilde Aksan, Çelikler ve Yenikalaycı (2019) araştırmalarında Fen Bilgisi öğretmen adaylarının geri dönüşüm konusundaki farkındalıklarının yeterli düzeyde olduğunu belirlemişlerdir.

Türkiye gibi gelişmekte olan ülkelerde, enerji tüketimindeki artışla ekonomik büyüme arasında güçlü bir ilişki vardır. Enerji talebinin ve ihtiyacının karşılanması için kaynakların verimli şekilde kullanılması gerekmektedir (Kılıçaslan, Peker ve Gün, 2011).

Özellikle gelecek nesilleri eğitecek olan öğretmen adaylarının sürdürülebilir kalkınma ve kaynakların tasarruflu kullanımına ilişkin farkındalıkları, bilgi seviyeleri ve bu konuya dair eylemlerinin tespiti büyük önem taşımaktadır. Alanyazın incelendiğinde de, dünya genelinde sürdürülebilir kalkınma ya da kaynakların tasarruflu kullanılması lisans eğitiminde büyük öneme sahiptir (Haigh, 2005). Ülkemizde eğitim fakültelerindeki bazı bölümler sürdürülebilir kalkınma ve kaynakları tasarruflu kullanma eğitimine önem vermekle beraber bu konuda bilincin oluşturulması konusunda birçok çalışma yapmaktadır. Özellikle Fen Bilgisi Öğretmenliği programında sürdürülebilir kalkınma ve kaynakların tasarruflu kullanımına yönelik konulara büyük önem verilmektedir. Ancak bu eğitim uygulamalı olmadığı için yeterli olmamaktadır. Bu doğrultuda, araştırmadan elde edilen bu sonuçlar doğrultusunda üniversitelerin eğitim fakültelerinde tüm öğretmen adaylarına sürdürülebilirlik, kaynakların tasarruflu kullanımı ve geri dönüşüm konusunda uygulamalı çalışmaların bilgi, beceri, tutum-değer bütünlüğü çerçevesinde programlı bir yaklaşımla yaptırılması önerilmektedir.

Ortaokul programlarında çevre eğitimi, kaynakların tasarruflu kullanımı ya da sürdürülebilir kalkınma adı altında seçmeli veya zorunlu bir ders bulunmamaktadır (Ünal, 2011). 2013 yılındaki Fen Bilimleri öğretim programında Fen-Teknoloji-Toplum-Çevre ilişkileri öğrenme alanına, gelecek nesiller için doğal kaynakların tasarruflu kullanımının faydalarını vurgulayan "sürdürülebilir kalkınma bilinci" adlı boyut bulunmaktadır (Eskicumalı, Demirtaş, Gür Erdoğan ve Arslan, 2014). 2013 yılında yayınlanan Fen Bilimleri müfredatında sürdürülebilir kalkınma bilinciyle hayatı boyunca araştırmaya ve öğrenmeye ilgi duyan fen okuryazarı bireylerin yetiştirilmesi amaçlanmaktadır (Milli Eğitim Bakanlığı [MEB], 2013). Ayrıca, 2018 yılında güncellenen Fen Bilimleri öğretim programında sürdürülebilirlik kavramı- 
nın daha fazla yer edinmesi ve bu konuda bilinç kazandırılması önemli olmuştur. 2018 yılında yayınlanan Fen Bilimleri öğretim programında "Birey, çeore ve toplum arasındaki karşılıkl etkileşimi fark ettirmek; toplum, ekonomi ve doğal kaynaklara ilişkin sürdürülebilir kalkınma bilincini geliştirmek" ifadesi yer almakla birlikte 8. sınıf programında; sürdürülebilir yaşam, kaynakların tasarruflu kullanımı ve geri dönüşüm konularına yer verilmiştir (MEB, 2018). Bu sonuçlardan hareketle, 2018 yılındaki Fen Bilimleri öğretim programının önceki programlara göre daha kapsamlı olmasına rağmen, kaynakların tasarruflu kullanımı konusunda yeterli olmadığ

$\mathrm{Bu}$ araştırmadan yola çıkılarak kaynakların tasarruflu kullanılması konusunda öğrencilere küçük yaşlardan itibaren farkındalık oluşturmakla sorumlu olan öğretmenlere, öğretmen adaylarına ve ailelere büyük görevler düşmektedir. Ayrıca, farkındalığı düşük olan toplumlarda bu durumu değiştirmek için kamu spotları (URL 2), aile eğitimleri, afişler vb. yaygınlaştırılabilir. 


\title{
EXTENDED ABSTRACT
}

\section{Opinions of Teacher Candidates in Science Education on the Efficient Use of Resources}

\author{
İbrahim Yüksel \\ Gazi University
}

Today, the need for energy is increasing, but energy resources are decreasing gradually. Therefore, it is necessary to use energy resources efficiently. The energy problem becomes a global problem with the increase in the world population, the development and use of technology. According to the United Nations "World Population Expectation" report published in 2019, the average world population, which is 7.7 billion, is expected to reach 9.7 billion in 2050 and 10.9 billion in 2100 (URL 1). In order to reduce the negative effects of this situation, the quality of the training to be carried out in order to use energy resources correctly and effectively is of great importance (Gunes, Alat, and Gozum, 2013).

All of the daily activities, from business to home life, from lighting to heating, are based on energy. The sources that provide the necessary energy are classified as renewable and non-renewable. From this point of view, it is stated that some energy sources are considered as non-renewable because their formation and renewal take a long time (Sarlak, 2012).

It takes a long time for natural resources to form. Considering the increase in the world population, the adequacy of natural resources remains limited. Therefore, resources should be used economically and should not be consumed unconsciously. Our resources spent unconsciously cause disruption of natural balance. According to Newborough and Probert (1994), the lack of awareness about energy arises from lack of education and indifference to this issue. In this respect, our schools form the basis for the development of energy awareness since childhood. Children grow up as environmentally sensitive and conscious citizens thanks to the education they receive from school (Dias, Mattos \& Balestieri, 2004). In this respect, the most important task falls on Science teachers and families who will provide training on the economical use of resources. 
The problem statement of the research can be expressed as "What are the opinions of the teacher candidates in the Science Education Department regarding the economical use of resources?" The purpose of the research is to determine the opinions of the teacher candidates in the Department of Science Education on the economical use of resources.

This research is qualitative and case study method was used. In addition to the in-depth analysis of an event, the case study can associate an event with a variety of facts and give the researched findings a holistic character. In addition, it provides an in-depth analysis of information that can be missed by other methods (Punch, 2014). The study was carried out with 127 volunteer teacher candidates studying in the Department of Science Education in the faculty of education of a state university in the spring semester of 2018-2019 academic year. The research was qualitative and case study method was used. As the data collection tool, the opinion form, including six open-ended questions, developed by the researcher by asking the opinions of 4 experts after an extensive literature analysis about the topic in Turkey was used and collected data were analyzed using content analysis. The answers obtained from the opinion form were coded in the study. Interpretations were made based on the codes. Teacher candidates were numbered between $\mathrm{TC}_{1} \ldots \mathrm{TC}_{127}$.

As a result of the research conducted in order to determine the opinions of teacher candidates in the Science Education Department on the economical use of resources, teacher candidates,

- Associate sustainable development with the concepts of economical use of resources, recycling, meeting the needs of future generations, contributing to the economy, and protecting the environment,

- Weren't taught about the economical use of resources,

- Associate water saving with "elimination of technical problems in taps, low water usage when brushing teeth, machine washing of dishes instead of hands, reduction of shower time, house cleaning",

- Stated that there was not enough training about the economical use of resources in universities in our country,

- Think that there is not enough information about the economical use of resources in the 2018 science course curriculum,

- Claim that the demand for wages is not sufficient for sustainable development. 
Based on this research, great duties fall on the teachers, teacher candidates and families who are responsible for raising awareness of students from a young age about the use of resources economically. Also, in lowawareness societies, public spots (URL 2), banners, etc. can be expanded to change this situation.

\section{Kaynakça / References}

2050'de Dünya Nüfusu 9,7 Milyar Olacak. (Haziran 18, 2019). Deustche Welle. https://www.dw.com/tr/2050de-d\%C3\%BCnya-n\%C3\%BCfusu97milyar-olacak/a-49245966 adresinden erişilmiştir.

7. Kıta Temsilcisi İstanbul'da. (Eylül 12, 2019). Koç Holding [Video] https://www.youtube.com/watch?v=oJ6-ZNtrBk8

Aksan, Z., Çelikler, D. ve Yenikalayc1, N. (2019). The determination on the science teaching candidates' awareness about the recycling. AJESI Anadolu Journal of Educational Sciences International, 9(2), 881-901. DOI: 10.18039/ajesi.583817

Deveci İ. (2018). Türkiye'de 2013 ve 2018 yılı fen bilimleri dersi öğretim programlarının temel öğeler açısından karşılaştırılması. Mersin Üniversitesi Eğitim Fakültesi Dergisi. 14(2), 799-825. DOI:10.17860/mersinefd.342260

Dias, R. A., Mattos, C. R. ve Balestieri J. A. P. (2004). Energy education: Breaking up the rational energy use barriers. Energy Policy, 31, 1339-1347.

Eskicumalı, A., Demirtaş, Z., Gür Erdoğan, D. ve Arslan, S. (2014). Fen ve teknoloji dersi öğretim programları ile yenilenen fen bilimleri dersi öğretim programlarının karşılaştırılması. International Journal of Human Sciences, 11(1), 1077-1094. DOI: 10.14687/ijhs.v11i1.2664

Güneş, T., Alat, K. ve Gözüm, A. İ. C. (2013). Fen öğretmeni adaylarına yönelik yenilenebilir enerji kaynakları tutum ölçeği: Geçerlilik ve güvenirlik çalışması. Ĕ̆itim Bilimleri Araştırmaları Dergisi (Uluslararası e dergi), 3(2),269-289.

Haigh, M. (2005). Greening the university curriculum. Appraising an International Movement, 29(1), 31-48.

https://doi.org/10.1080/03098260500030355 
Kılıçaslan, M., Peker, E. A. ve Gün, F. (2011). Yenilenebilir enerji kaynaklarının çevreye olan katkısına ilişkin ilköğretim öğrenci görüşleri: Samsun ili örneği. Researchgate,

https://www.researchgate.net/publication/329921371_yenilenebilir_e nerji_kaynaklarinin_cevreye_olan_katkisina_iliskin_ilkogretim_ogre nci_gorusleri_samsun_ili_ornegi adresinden erişilmiştir.

Miles, M. B. ve Huberman, A. M. (1994). An expanded sourcebook: Qualitative data analysis (2nd edition). Thousand Oaks, CA: Sage Publications.

Milli Eğitim Bakanlığı [MEB] (2013). Illköğretim Fen ve Teknoloji Dersi (6, 7 ve 8. Sınıflar) Öğretim Programı. Ankara.

Milli Eğitim Bakanlığı [MEB] (2018). Fen bilimleri dersi öğretim programı (İlkokul ve ortaokul 3, 4, 5, 6, 7 ve 8. sinıflar). Ankara: Millî Eğitim Bakanlığ1 Temel Eğitim Genel Müdürlüğ̈̈.

Newborough, M. ve Probert, D. (1994). Purposeful energy education in the UK. Applied Energy, 48, 243-259.

Punch, K. F. (2014). Introduction to social research: Quantitative $\mathcal{E}$ qualitative approaches, (3th edition). London: Sage Publications.

Şarlak, Z. (2012). Enerji tasarrufu. (D. H. Işılak ed.), (2. Baskı), İstanbul, Nakış Ofset.www.aep.gov.tr/wp-content/uploads/2012/10/03_03_enerjitasarrufu.pdf adresinden erişilmiştir.

Ünal, F. (2011). İlköğretimde sürdürülebilir çevre eğitiminin yeri. Bilim ve Aklın Aydınlığında Ĕ̆itim, 132, 68-73.

\section{Kaynakça Bilgisi / Citation Information}

Yüksel, İ. (2020). Fen bilgisi eğitimi anabilim dalı'ndaki öğretmen adaylarının kaynakların tasarruflu kullanımı hakkındaki görüşleri. OPUS-Uluslararası Toplum Araştırmaları Dergisi, 15(22), 1015-1031. DOI: 10.26466/opus.648555 